\title{
Delay and block of cardiac impulse caused by enhanced phase- 4 depolarization in the His-Purkinje system
}

\author{
Andres Kretz, ${ }^{1}$ Hector O. Da Ruos, ${ }^{1}$ and Jose R. Leguizamon Palumbo ${ }^{+}$ \\ From the Department of Cardiology, Hospital Argerich, Buenos Aires; \\ and the Coronary Care Unit, Hospital de Vicente Lopez, Buenos Aires, Argentina
}

The underlying mechanism of bradycardia-dependent bundle-branch and paroxysmal atrioventricular block appears to be enhancement of phase-4 depolarization in a branch or in a natural or acquired monofascicular pathway.

Clinical records of these forms of impaired conduction occurring in the bundle-branches, with either longer or shorter cardiac cycle lengths, are presented and analysed. These also include the combination of Mobitz type I atrioventricular block with variable degrees of bundle-branch block, as a representative example of narrow ventricular escape beats firing in the zone where prominent diastolic depolarization is present.

Spontaneous depolarization during phase- 4 is the electrophysiological mechanism which enables the automatic cells to be effective or latent pacemakers (West, I955a, b). Occasionally, under certain pathological conditions, the ventricular specialized conduction system may exhibit prominent diastolic depolarization (Weidmann, 1955; Singer, Lazzara, and Hoffman, 1967; Wennemark and Ruesta, 197I), the mechanism underlying bradycardia-dependent bundle-branch block (Massumi, I968; Elizari et al., I968; Sarachek, 1970; Schamroth and Lewis, I971; El-Sherif, 1972; Rosenbaum et al., 1973b; Barold and Schamroth, 1973). The development of atrioventricular block due to enhanced phase-4 depolarization (Singer et al., I967) occurs either in the His bundle, or in a branch or division of the conducting system when the remaining routes are blocked.

Association of enhanced automaticity and impaired conductivity owing to the development of generalized diastolic depolarization in the higher parts of the main intraventricular conduction fascicles, may be clinically exemplified by narrow ventricular ectopic beats located in the zone showing conduction delays.

This paper presents electrocardiograms of pat-

Received I May I974.

1 Present address: Department of Experimental Medicine, Instituto de Investigaciones Medicas, Facultad de Medicina, Universidad de Buenos Aires, Buenos Aires, Argentina. ients with bradycardia-dependent block, which can be explained in terms of phase- 4 depolarization, and discussions on the concepts related to this electrophysiological mechanism based upon the corresponding records.

\section{Subjects and methods}

The group consisted of II patients, of whom 6 had bradycardia-dependent bundle-branch block (Table I), and 5 had bradycardia-dependent paroxysmal atrioventricular block (Table 2). The main clinical and electrocardiographic features are summarized in these Tables. All electrocardiograms were recorded with a Sanborn Model 296 direct writing electrocardiograph at a paper speed of $25 \mathrm{~mm} / \mathrm{second}$. Vectorcardiograms in the three-plane projections were recorded in the supine position by the Frank system, with a Hewlett-Packard I520-A machine, using the fourth intercostal space.

Bipolar recordings of the bundle of $\mathrm{His}$ were obtained as previously described (Scherlag et al., 1969), with a $4 \mathrm{~F}$ bipolar pacing catheter. Each bipolar lead was connected to the AC inputs of a multichannel oscilloscopic photographic recorder, with filter frequency set at 40 and $200 \mathrm{cycles} / \mathrm{sec}$. Records were taken at $100 \mathrm{~mm} / \mathrm{sec}$.

All analysed beats were of sinoatrial origin. $R R$ intervals were measured to determine the ranges of normal and aberrant intraventricular conduction in the bradycardia-dependent bundle-branch block. The same measurements were performed with the RP intervals in bradycardia-dependent paroxysmal atrioventricular block. In several cases, slowing of the heart rate was achieved by carotid sinus pressure. 
TABLE I Bradycardia-dependent bundle-branch block

\begin{tabular}{|c|c|c|c|c|c|c|c|}
\hline $\begin{array}{l}\text { Case } \\
\text { No. }\end{array}$ & $\begin{array}{l}\text { Age } \\
(y r)\end{array}$ & Sex & Diagnosis & $\begin{array}{l}\text { Intraventricular } \\
\text { conduction aberrancy }\end{array}$ & $\begin{array}{l}\text { Conduction } \\
\text { Phase-3 } \\
\text { block }\end{array}$ & $\begin{array}{l}\text { anges in bundle } \\
\text { Normal } \\
\text { conduction }\end{array}$ & $\begin{array}{l}\text { Phase 4- } \\
\text { block }\end{array}$ \\
\hline $\begin{array}{l}1 \\
2 \\
3 \\
4 \\
5 \\
6\end{array}$ & $\begin{array}{l}47 \\
45 \\
61 \\
64 \\
58 \\
53\end{array}$ & $\begin{array}{l}M \\
M \\
F \\
M \\
M \\
M\end{array}$ & $\begin{array}{l}\text { Coronary heart disease } \\
\text { Aortic disease } \\
\text { Coronary heart disease } \\
\text { Coronary heart disease } \\
\text { Coronary heart disease } \\
\text { Coronary heart disease }\end{array}$ & $\begin{array}{l}\text { Left bundle-branch block } \\
\text { Left bundle-branch block } \\
\text { Left bundle-branch block } \\
\text { Right bundle-branch block } \\
\text { Left bundle-branch block } \\
\text { Right bundle-branch block }\end{array}$ & $\begin{array}{l}0.84-1.40 \\
- \\
0.62-0.80 \\
0.54-1.20 \\
0.52-0.84 \\
0.58-0.64\end{array}$ & $\begin{array}{l}1 \cdot 22-2 \cdot 42 \\
0 \cdot 75-1 \cdot 18 \\
0 \cdot 70-1 \cdot 42 \\
I \cdot 18-2 \cdot 04 \\
0 \cdot 74-1 \cdot 28 \\
-\end{array}$ & $\begin{array}{l}2 \cdot 02-5 \cdot 80 \\
I \cdot 16-1 \cdot 30 \\
I \cdot 34-3 \cdot 56 \\
I \cdot 84-4 \cdot 08 \\
I \cdot 20-8 \cdot 02 \\
0 \cdot 84-1 \cdot 24\end{array}$ \\
\hline
\end{tabular}

The conduction ranges in bundle are expressed throughout as $R R$ intervals in seconds.

TABLE 2 Bradycardia-dependent atrioventricular block

\begin{tabular}{|c|c|c|c|c|c|c|c|c|c|c|}
\hline \multirow{2}{*}{$\begin{array}{l}\text { Case } \\
\text { No. }\end{array}$} & \multirow[t]{2}{*}{ Age } & \multirow[t]{2}{*}{ Sex } & \multirow{2}{*}{$\begin{array}{l}\text { Intraventricular } \\
\text { aberrancy }\end{array}$} & \multirow[t]{2}{*}{ Diagnosis } & \multirow{2}{*}{\multicolumn{2}{|c|}{$\begin{array}{l}\text { Intervals (ms) } \\
A H \quad H V\end{array}$}} & \multirow{2}{*}{$P R$} & \multicolumn{3}{|c|}{$A V$ conduction ranges } \\
\hline & & & & & & & & $\begin{array}{l}\text { Early } \\
\text { AV block } \\
\text { zone }\end{array}$ & $A V$ cond. & $\begin{array}{l}\text { Tardy } \\
\text { AV block } \\
\text { zone }\end{array}$ \\
\hline $\mathbf{I}$ & 29 & $\mathbf{M}$ & $\begin{array}{l}\text { Right bundle-branch } \\
\text { block }+ \text { left } \\
\text { posterior hemi- } \\
\text { block }\end{array}$ & Cardiomyopathy & - & - & 0.24 & $0.16-0.44$ & $0.36-I \cdot 30$ & $I \cdot 22-I \cdot 96$ \\
\hline 2 & 78 & $\mathbf{M}$ & $\begin{array}{l}\text { Right bundle-branch } \\
\text { block }+ \text { left } \\
\text { anterior }\end{array}$ & Idiopathic chronic & & & & & & \\
\hline 3 & 64 & $\mathbf{F}$ & $\begin{array}{l}\text { hemiblock } \\
\text { Right bundle-branch }\end{array}$ & AV block & IIo & 80 & 0.19 & $0.20-0.50$ & $0.54-I \cdot 08$ & $I \cdot I I-2 \cdot 88$ \\
\hline 4 & 80 & $M$ & $\begin{array}{l}\text { block }+ \text { left } \\
\text { posterior hemiblock }\end{array}$ & $\begin{array}{l}\text { Coronary heart } \\
\text { disease }\end{array}$ & 100 & 80 & 0.18 & $0.24-0.34$ & $0.32-0.64$ & $0.56-I \cdot 14$ \\
\hline 4 & 80 & $M$ & $\begin{array}{l}\text { Right bundle-branch } \\
\text { block }+ \text { left } \\
\text { anterior hemiblock }\end{array}$ & $\begin{array}{l}\text { Idiopathic chronic } \\
\text { AV block }\end{array}$ & 一 & - & 0.22 & $0.23-0.34$ & $0.32-0.58$ & $0.56-1.04$ \\
\hline 5 & 65 & $\mathbf{M}$ & $\begin{array}{l}\text { Left bundle-branch } \\
\text { block }\end{array}$ & $\begin{array}{l}\text { Coronary heart } \\
\text { disease }\end{array}$ & - & - & & $0.18-0.33$ & $0.30-0.76$ & $0.72-1.09$ \\
\hline
\end{tabular}

Atrioventricular conduction ranges are expressed throughout as RP intervals in seconds.

\section{Intermittent rate-dependent bundle-branch block}

Case I Electrocardiographic and vectorcardiographic study (Fig. IA), performed during first admission to hospital of a 49-year-old patient with a two-year history of angina pectoris, indicated spontaneous intermittent left bundle-branch block and anteroseptal ischaemia. A long tracing (Fig. 2), performed a week later during which vagal manoeuvres were carried out (Comeau, Hamilton, and White, 1938; Dressler, 1959), showed left bundle-branch block at the shortest and longest diastolic intervals; at an intermediate range the intraventricular conduction was normal. Three conduction ranges were observed: the first, with $R R$ intervals between 0.84 and $I .40$ sec and left bundle-branch block aberrancy; the second, between $I \cdot 22$ and $2.42 \mathrm{sec}$ with normal intraventricular conduction; and the third, in which paradoxically the left bundle-branch block reappeared between 2.02 and 5.80 sec. In the graph (Fig. IB) obtained from the above-mentioned study, representing 954 beats of sinoatrial origin, the three conduction areas previously described are delimited: a) phase-3 left bundle-branch block (beats arriving at the left bundle-branch during its absolute or relative refractory period (Katz and Pick, I956)); b) normal intraventricular conduction; and c) phase-4 left bundlebranch block (impulses reaching fibres of the left bundlebranch with reduced levels of membrane potential caused by spontaneous diastolic depolarization).

Sinus impulses with left bundle-branch block aberrancy, which overlap with the beats corresponding to both ends of the normal conduction zone, should be noted (Rosenbaum et al., r973a; Garcia and Rosenbaum, I972).

Two months later when the patient was readmitted 
because of increased symptoms, left bundle-branch block was registered which was not modified by changes in cardiac frequency. This electrocardiographic pattern remained unchanged in follow-up examinations performed during the next year and a half.

This case typifies a bradycardia-dependent left bundle-branch block which has the following outstanding features: $I$ ) intraventricular aberrancy occurring simultaneously with pronounced prolongation of the cardiac cycle length; and 2) transitory stage of the phenomenon of bradycardia-dependent left bundlebranch block.

Case 2 A 45-year-old patient with aortic valve disease, cardiac failure, and syncopal attacks : basic tracing (Fig. 3) shows a sinus rhythm with first degree atrioventricular
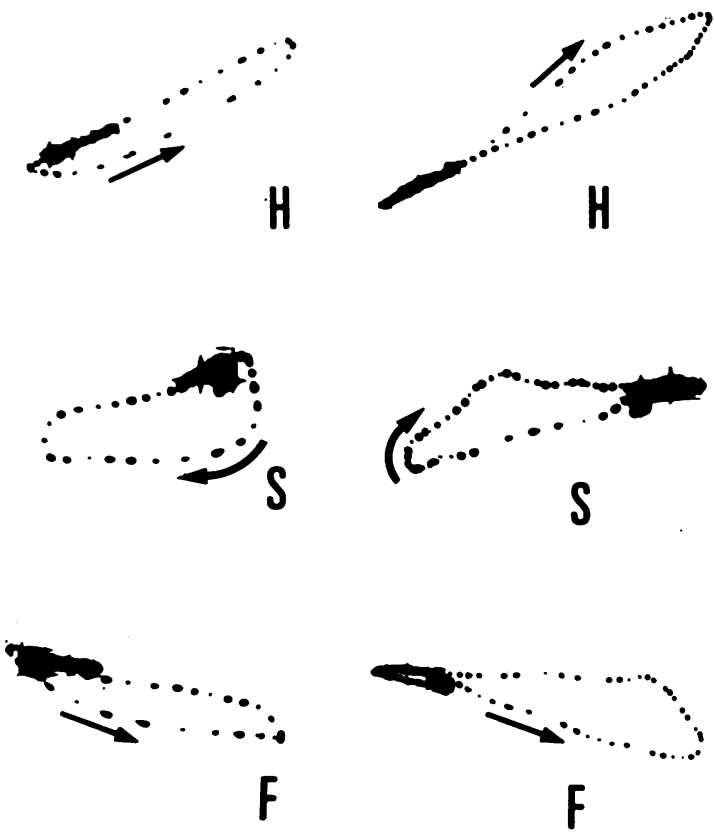

A
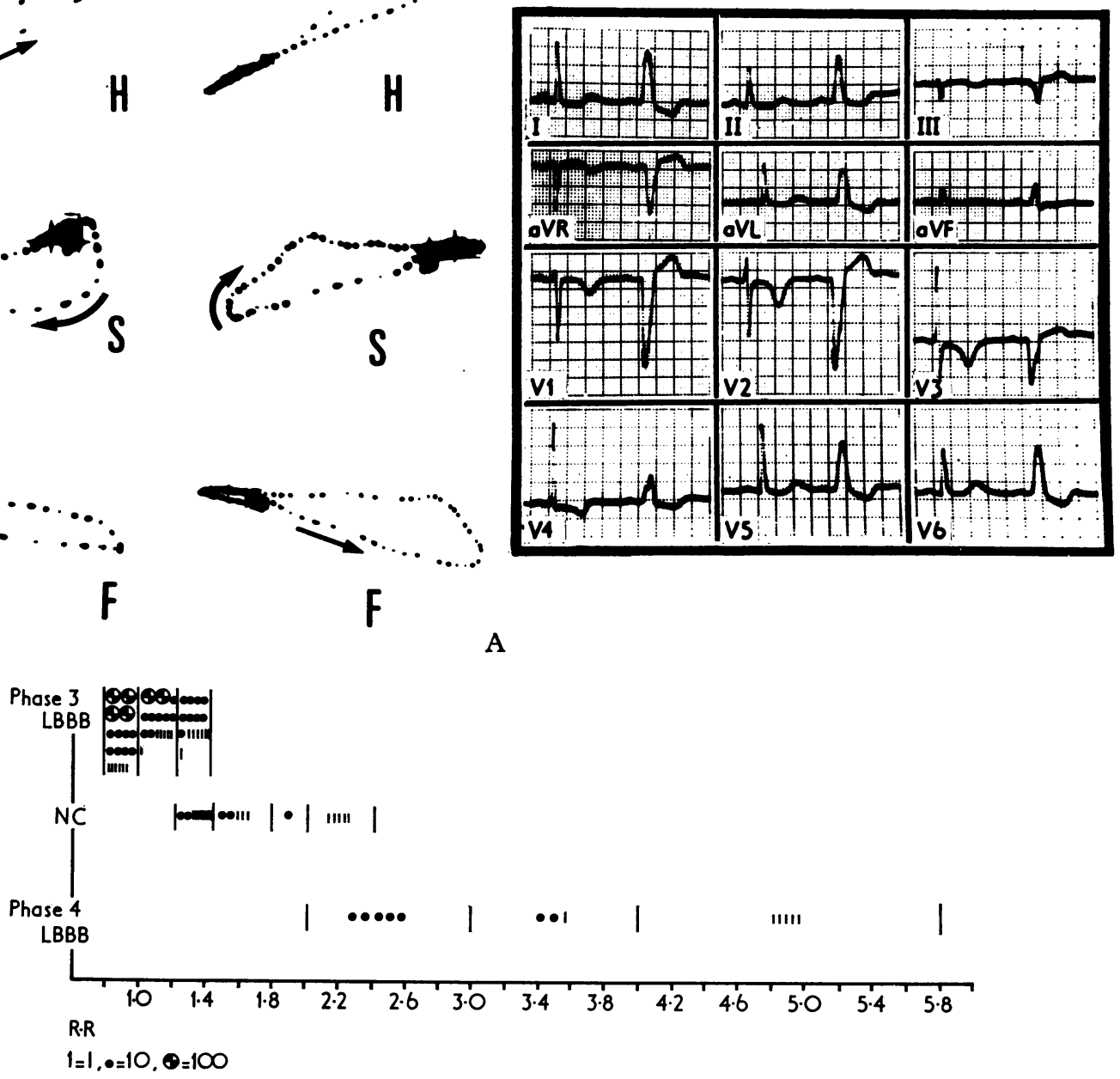

B

FIG. I Panel A: Electrocardiogram and vectorcardiogram with intermittent left bundle-branch block. In each lead the first beat is without, and the second with, left bundle-branch block. Inverted $T$ waves in leads $V_{I}$ to $V_{4}$ are observed in the normal conducted beats. Panel B: Graphic representation of 954 conducted beats with normal intraventricular conduction, and left bundlebranch block aberrancy according to their corresponding $R R$ intervals. Time intervals are depicted in hundredths of seconds. NC, normal conduction; phase-3 LBBB, phase-3 left bundle-branch block; phase-4 LBBB, phase-4 left bundle-branch block; RR, RR intervals. 
A.

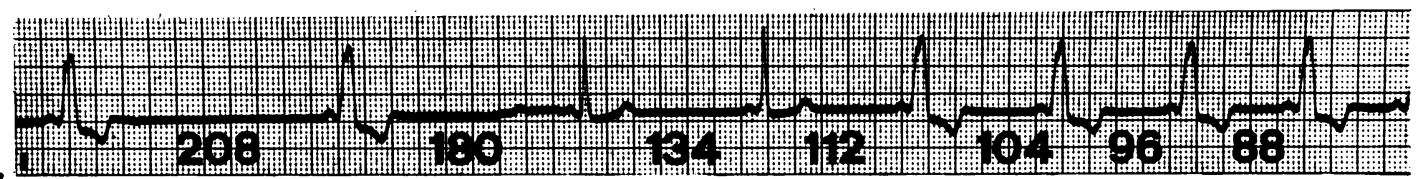

B.
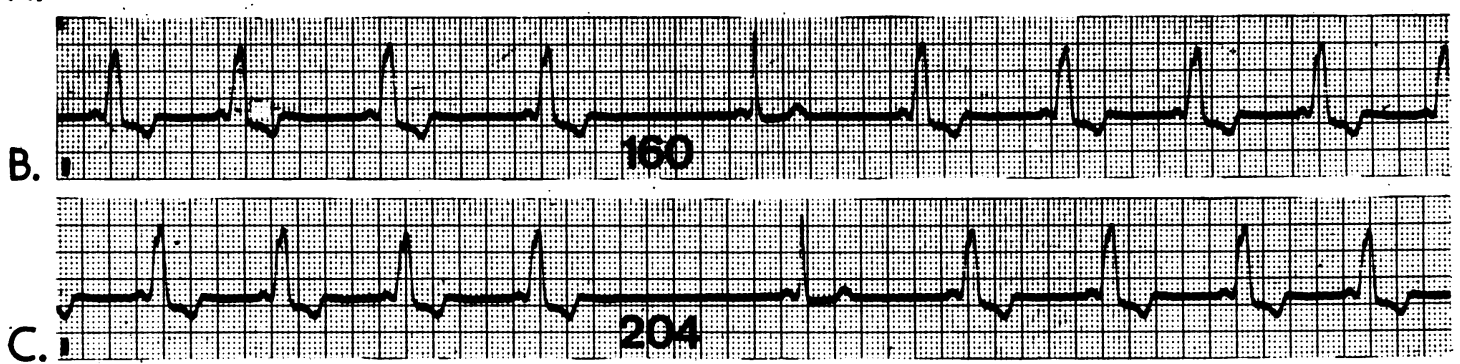

c. In II

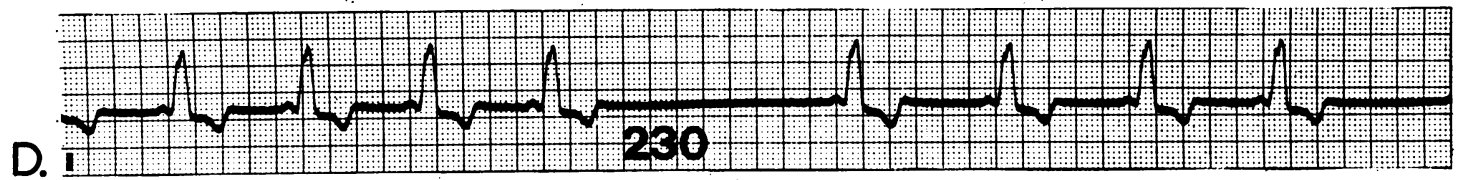

D.

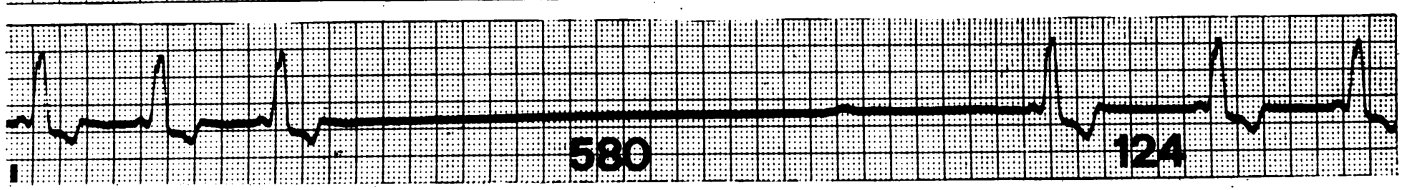

E.

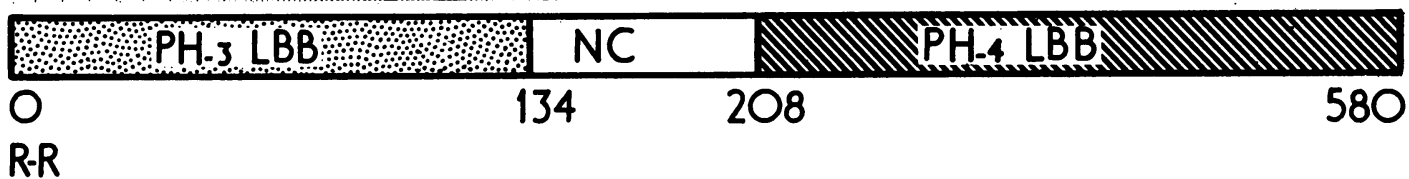

R-R

FIG. $2 A$ to $E$, discontinuous record of lead I. Tracings of conducted sinus beats presenting normal and aberrant $Q R S$ complexes with left bundle-branch block pattern according to previous cycle length. The distribution of the mentioned beats are schematically represented at the bottom of this figure. See text for further explanation. NC, normal conduction; PH-3 LBBB, phase-3 left bundle-branch block; PH-4 LBBB, phase-4 left bundle-branch block; $R R, R R$ intervals.

block (PR $0.28 \mathrm{sec}$ ) left ventricular hypertrophy, and incomplete left bundle-branch block. An electrocardiogram performed two days later (Fig. 4) shows, in strips $\mathrm{A}, \mathrm{B}$, and $\mathrm{C}$, conducted beats preceded by identical $\mathbf{P}$ waves with constant $P R$ intervals and different degrees of left bundle-branch block starting from an $R R$ interval of $I \cdot I 6 \mathrm{sec}$. The variability of conduction disturbance is directly related to the previous diastolic pause; greater degrees of left bundle-branch block aberrancy are preceded by longer $R R$ intervals.

In strip $\mathrm{D}$ an increase in the sinus frequency establishes a 2:I atrioventricular block and the conducted beats also present variable degrees of left bundle-branch block.

A new record obtained three days later (Fig. 5A) showed different degrees of bradycardia-dependent left bundle-branch block and the appearance of narrow ventricular escape beats with pure incomplete right bundlebranch block pattern starting from an RR interval of
$\mathbf{I} \cdot 30 \mathrm{sec}$. In addition, atrioventricular dissociation with a similar ectopic rhythm firing at a rate of about $50 / \mathrm{min}$ was recorded during the same study (Fig. 5C). Two months later, while the patient was receiving digitalis (Fig. 6, strip A), prolongation of first degree atrioventricular block up to $0.32 \mathrm{sec}$ was noticed. In strip B, an increment of the sinus frequency causes a second degree atrioventricular block with a $3: 2$ and $4: 3$ LucianiWenckebach ratio. The fluctuations in diastolic pauses originated by the dropped $P$ waves determine the appearance of variable degrees of left bundle-branch block in the beats, which reinitiate the cycle maintaining a constant $P R$ interval of $0.32 \mathrm{sec}$. In strip $C$ a further increase in the sinus frequency establishes a $2:$ I atrioventricular block with similar characteristics to the one observed in Fig. 4, strip D. During this study a vectorcardiogram was performed simultaneously, registering beats of sinoatrial origin with progressive left bundle-branch block aberrancy. 

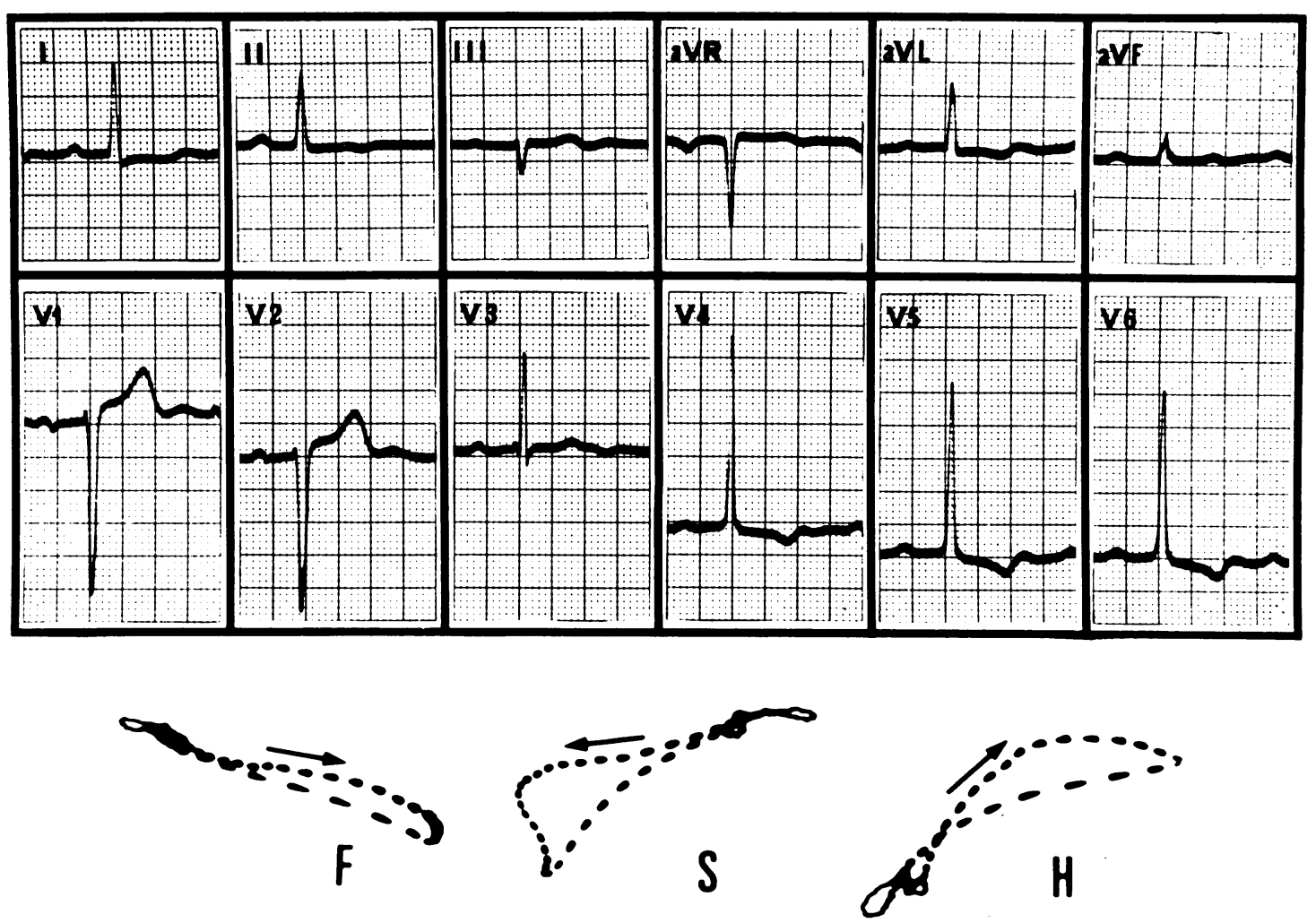

FIG. 3 Electrovectorcardiogram showing sinus rhythm, left ventricular hypertrophy, and incomplete left bundle-branch block with first degree atrioventricular block.

A.
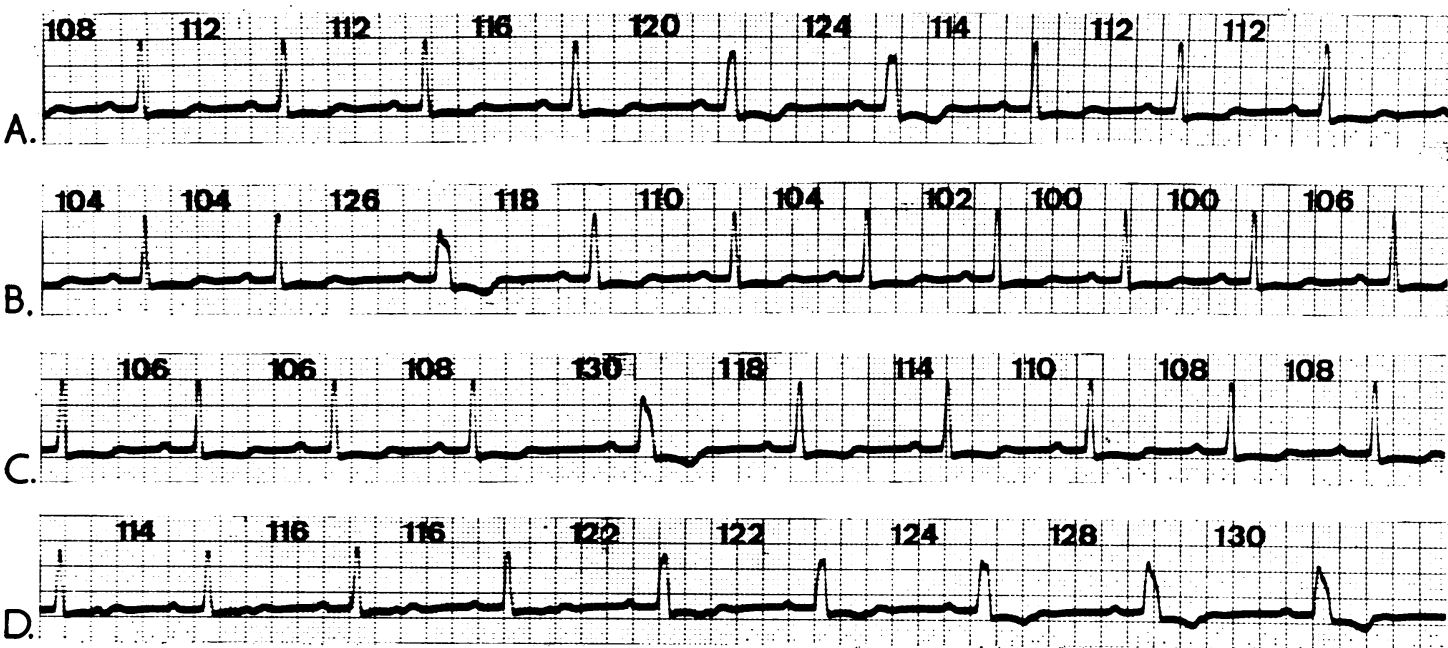

FI G. 4 Electrocardiogram (discontinuous strips of standard lead I) showing in $A, B, C$, and $D$, variable degrees of left bundle-branch block aberrancy related to previous cycle length. See text for further explanation. 
B.

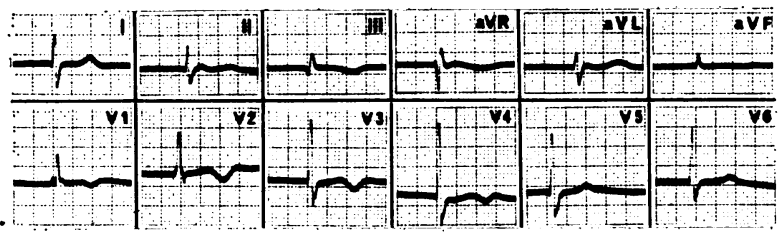

A.
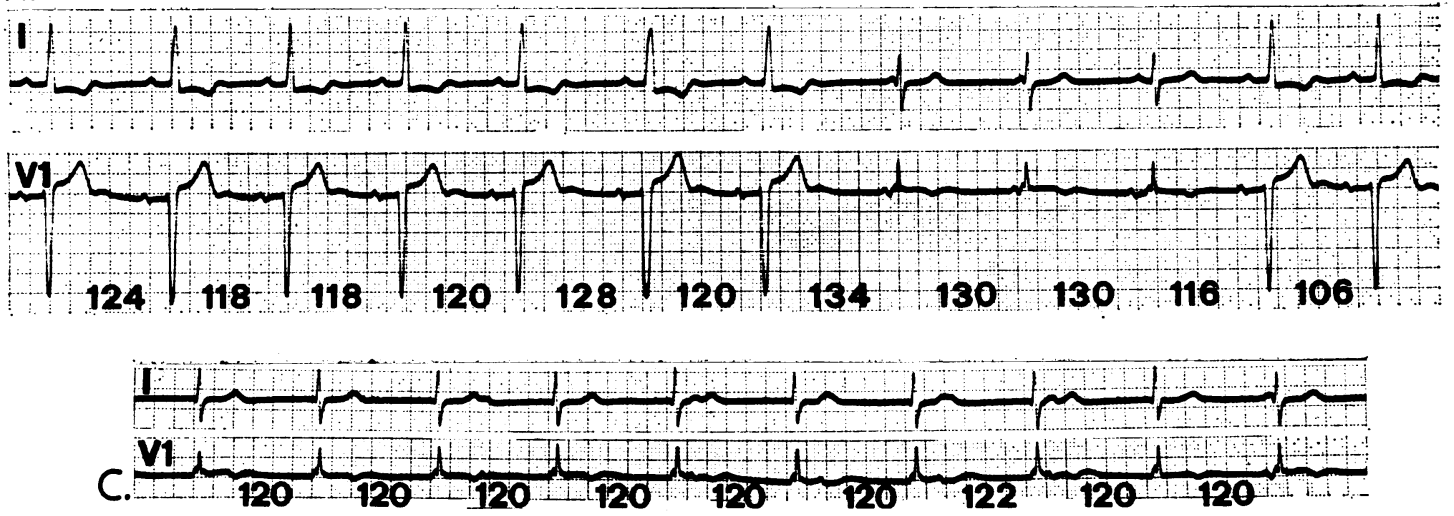

FIG. 5 Panel A: Simultaneous recording of leads I and VI. Variable degrees of bradycardiadependent left bundle-branch block developed during induced slowing of the heart rate (carotid sinus pressure). Appearance of narrow ventricular escape beats exhibiting pure incomplete right bundle-branch block aberrancy, preceded by diastolic intervals exceeding $I \cdot 28$ sec. Panel B: Twelve lead electrocardiogram of narrow ventricular escape beats with pure incomplete right bundle-branch block pattern. Panel C: Atrioventricular dissociation. Narrow ventricular ectopic rhythm with pure incomplete right bundle-branch block configuration discharging at a rate of about 50 beats/min. (RR intervals are indicated in hundredths of seconds.)

This case presents the following outstanding features: I) variable degrees of aberrant intraventricular conduction, taking place conjointly with slight increases in cardiac cycle length; 2) coexistence of Luciani-Wenckebach phenomenon with variable degrees of bradycardiadependent left bundle-branch block; 3) differing degrees of phase-4 left bundle-branch block, associated with narrow ventricular ectopic beats exhibiting pure incomplete right bundle-branch block configuration; 4) inability to obtain phase 3 left bundle-branch block (tachycardia-dependent left bundle-branch block) because of the development of $2:$ I atrioventricular block when heart rate is increased.

\section{Rate-dependent atrioventricular block}

Case I A 27-year-old man with Chagasic cardiomyopathy had sinus arrhythmia and advanced atrioventricular block, requiring a permanent demand type pacemaker. During his stay in hospital paroxysmal episodes of atrioventricular block were observed (Fig. 7), which alternated with complete atrioventricular block and $\mathrm{I}: \mathrm{I}$ atrioventricular conduction. The electrocardiogram (Fig. 8A) clearly reflects disturbances of the intraventricular conduction characterized by a $P R$ interval of $0.24 \mathrm{sec}$ and right bundle-branch block, with block in the posterior inferior division of the left bundle-branch (left posterior hemiblock). In a long tracing recorded during a series of syncopal attacks (Fig. 7A), it may be observed that the first conducted sinus impulse (Ist) is followed by an episode of sinus depression which initiated a period of ventricular asystole, interrupted by a notched $P$ wave (2nd) representing a blocked atrial beat with an RP interval of $I \cdot 34 \mathrm{sec}$. The following $P$ wave $(3 \mathrm{rd})$ is also blocked, thus resulting in a diastolic pause which is terminated by a ventricular escape beat. The next sinus impulse (4th) which follows the escape beat is conducted to the ventricles with an RP interval of $0.50 \mathrm{sec}$, the succeeding two atrial beats ( 5 th to 6 th) also being conducted. Then a new episode of sinus depression produces a similar sequence which is repeated in strips $\mathbf{A}$ and $\mathbf{B}$. Periods of ventricular asystole varying in duration from 2.55 to $8.20 \mathrm{sec}$, provoked either by spontaneous sinus depression (strips A and B), or premature artificial stimulus (strip C), can be observed all through this figure.

To establish the range of propagation and blockage of atrial impulses in the atrioventricular conduction system, 1224 beats were analysed (Fig. 8B). The immediate post-escape conduction was tabulated independently and PP and PR intervals were also measured. Atrial post-escape impulses (Fig. 8B above dotted line) 

A. $\mathrm{F}$

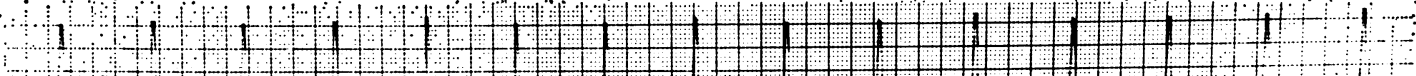
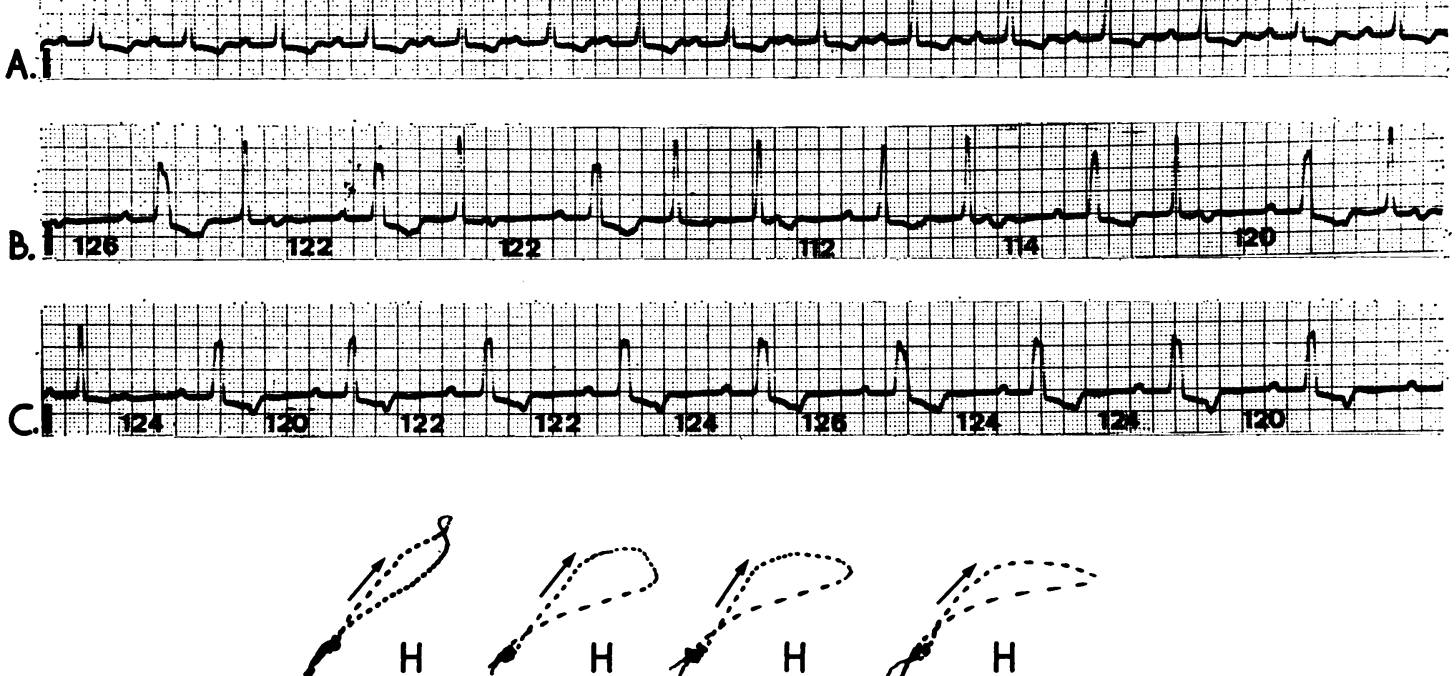

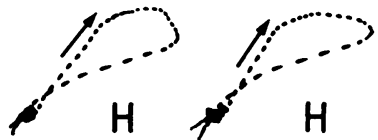

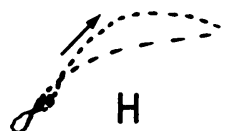

FIG. 6 Three strips of lead I selected from continuous record. A) Sinoatrial beats with first degree atrioventricular block. B) Variable degrees of bradycardia-dependent left bundle-branch block in the first sequence beat of Luciani-Wenckebach period. C) 2:I atrioventricular block with different degrees of left bundle-branch block aberrancy according to previous diastolic length. Bottom: Vectorcardiogram: horizontal plane. From right to left, different degrees of left bundle-branch block.
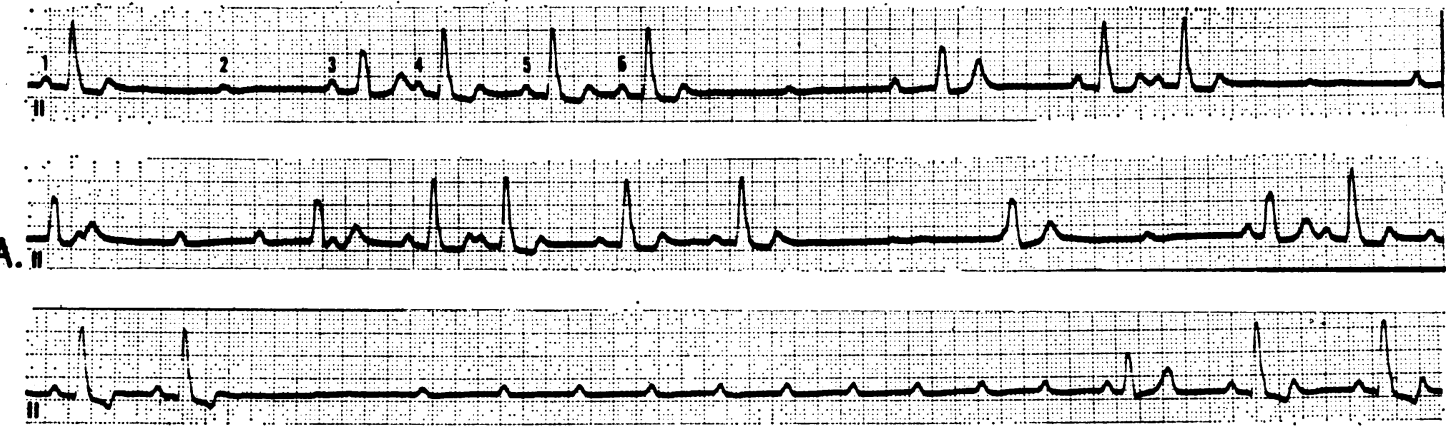

B. $\pi$

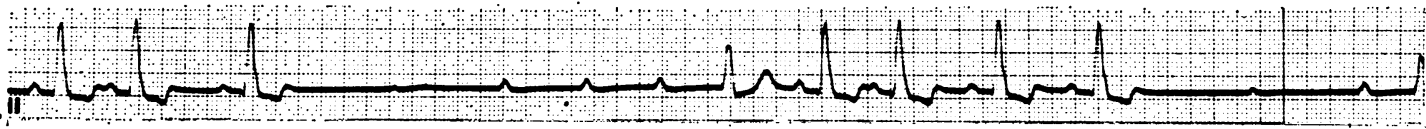

C.

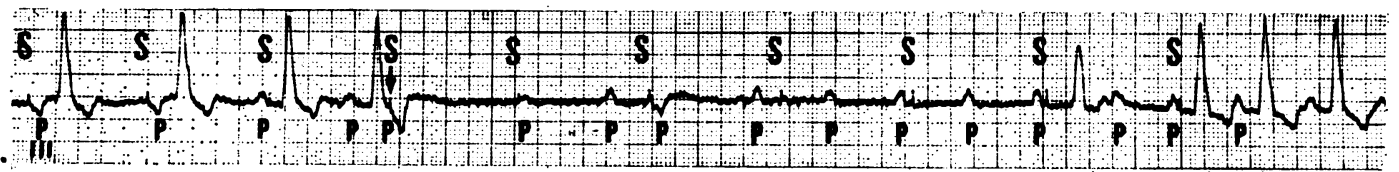

FIG. 7 Panels A and B: Short and longer runs of paroxysmal atrioventricular block all initiated by sponianeous sinus depression. Panel C: Same event induced by artificial premature atrial impulse (arrow). See text for further explanation. 
present an early atrioventricular blocked zone; another one of conducted beats; and a third late atrioventricular blocked zone. The rest of the studied beats (Fig. 8B below dotted line) show an atrioventricular conduction zone followed by another one of blocked beats. In this group, early atrioventricular blocked zone is not observed, since spontaneous ventricular asystole was always initiated by depression of the sinus pacemaker.
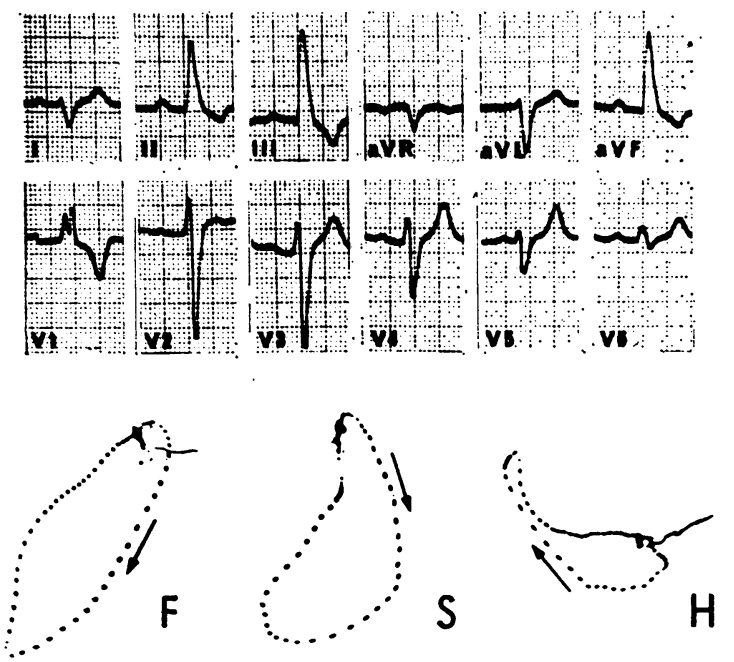

A
Analysing all the beats in the graph corresponding to Fig. 8B, the existence of a conduction zone and two blocked areas can be seen. Blocked atrial impulses overlapping the beats corresponding to both ends of the atrioventricular conduction zone may be observed. Sinus impulses (below dotted line) which occur after an RP interval longer than $I \cdot 20 \mathrm{sec}$ or shorter than $0.40 \mathrm{sec}$, are blocked, and those (above dotted line) occurring with an RP interval between $0.40 \mathrm{sec}$ and $\mathrm{r} \cdot 30 \mathrm{sec}$ after a ventricular escape beat, are conducted. Therefore, only atrial impulses which follow a ventricular escape beat or another supraventricular conducted beat within a limited period are transmitted to the ventricles.

This case exemplifies paroxysmal atrioventricular block; its more remarkable features being: $\mathrm{I}$ ) episodes of paroxysmal atrioventricular block originated by changes in atrial frequency; 2) a ventricular escape beat followed by sinus impulse with an adequate time relation to reinitiate the atrioventricular conduction; 3) transitoriness of paroxysmal atrioventricular block periods, alternating with I:I atrioventricular conduction and complete atrioventricular block.

Case 2 This 78-year-old patient had Adams-Stokes episodes before his paroxysmal atrioventricular block was recognized. These disappeared after the implantation of a pacemaker. Electrocardiogram and vectorcardiogram on admission (Fig. 9) showed right bundlebranch block with left anterior hemiblock, and a PR interval of $0.19 \mathrm{sec}$; it should also be stressed that a prolonged HV time of $80 \mathrm{msec}$ was recorded.

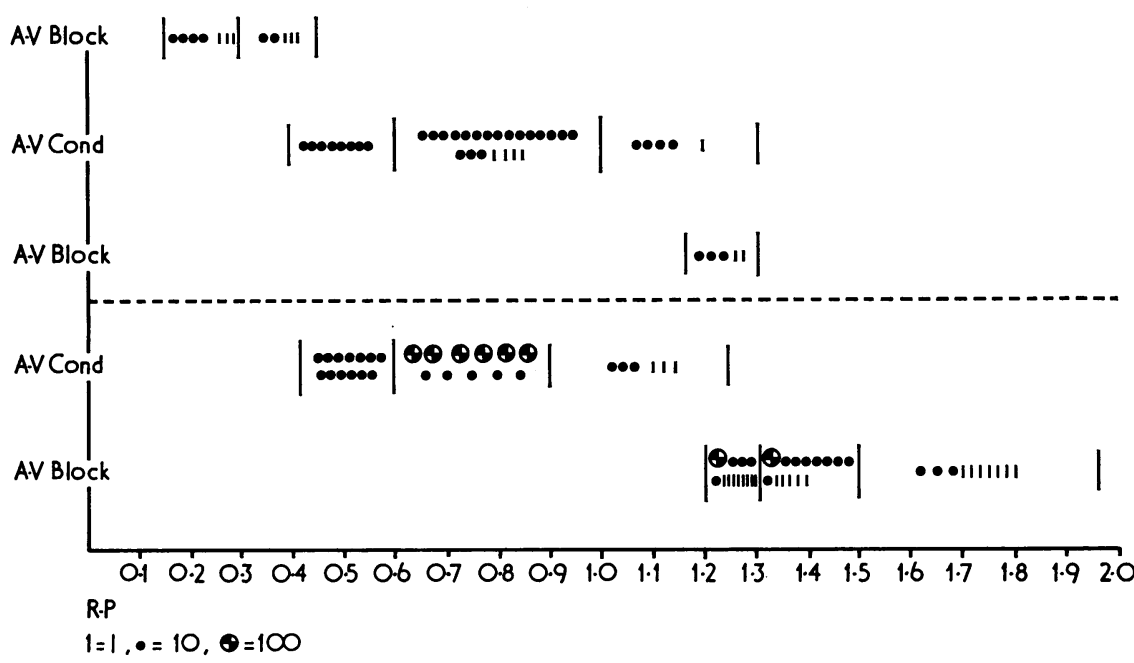

B

FIG. 8 Panel A: Electrovectorcardiogram of right bundle-branch block with left posterior hemiblock and first degree atrioventricular block. Panel B: Graphic representation of $R P$ intervals corresponding to 1224 conducted and non-conducted supraventricular impulses. Postescape conducted and blocked beats are above the dotted line. Time intervals are depicted in hundredths of seconds. See text for detailed discussion. Abbreviations, $A-V$ block, atrioventricular block; $A-V$ cond, atrioventricular conduction; $R P, R P$ intervals. 
Fig. Io, corresponding to episodes of paroxysmal atrioventricular block, indicates how the acceleration or decrease of atrial frequency gives rise to periods of ventricular asystole. Atrioventricular conduction is reestablished when a $P$ wave, occurring after the ventricular escape beat, and maintaining a critical RP interval with the latter, is conducted to the ventricles.

To determine the range of conduction or blockage in the atrioventricular conduction system, 628 atrial beats were studied, delimiting: a) a blocking range between 0.20 and $0.50 \mathrm{sec}: \mathrm{b}$ ) an atrioventricular conduction range from 0.54 to $\mathrm{I} .08 \mathrm{sec}$, and again c) a blocking range between $I \cdot I I$ and $2 \cdot 88 \mathrm{sec}$.

This case presents the following features: I) paroxysmal atrioventricular block caused by variations of the atrial frequency; 2) termination of the atrioventricular block episode conditioned by the appearance of a ventricular escape beat and its timing with the first
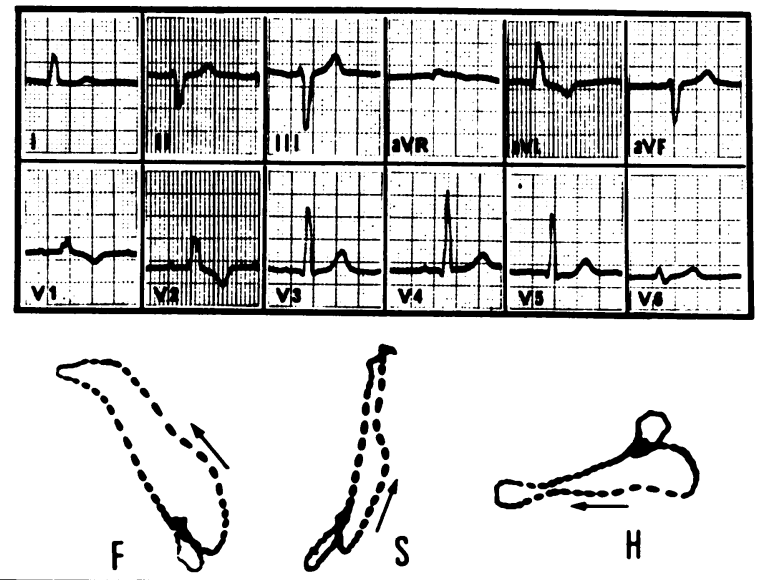

H

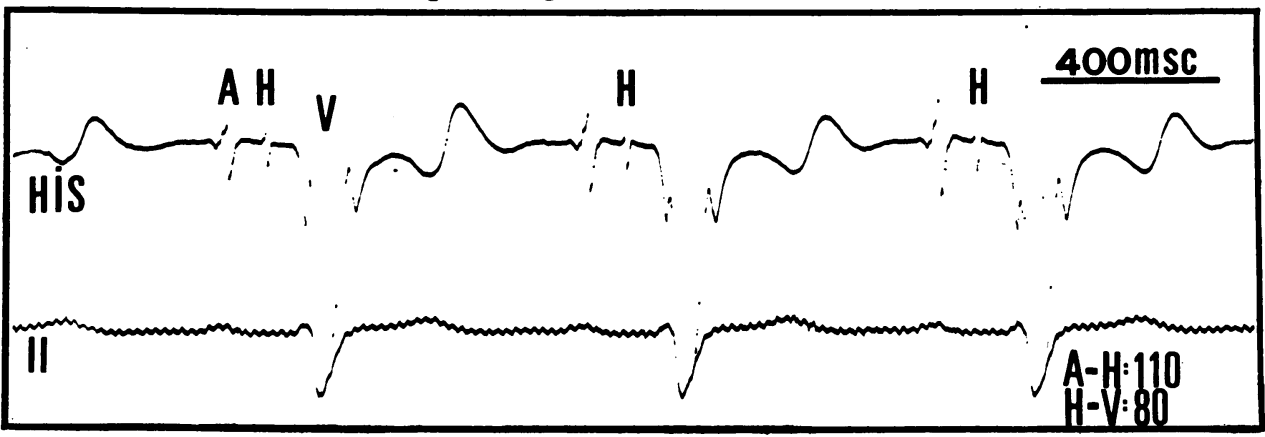

FIG. 9 Electrocardiogram and vectorcardiogram of right bundle-branch block with left anterior hemiblock and a PR interval of 0.19 sec. Bottom tracing: His bundle electrogram $(H B E)$ recorded simultaneously with lead II.
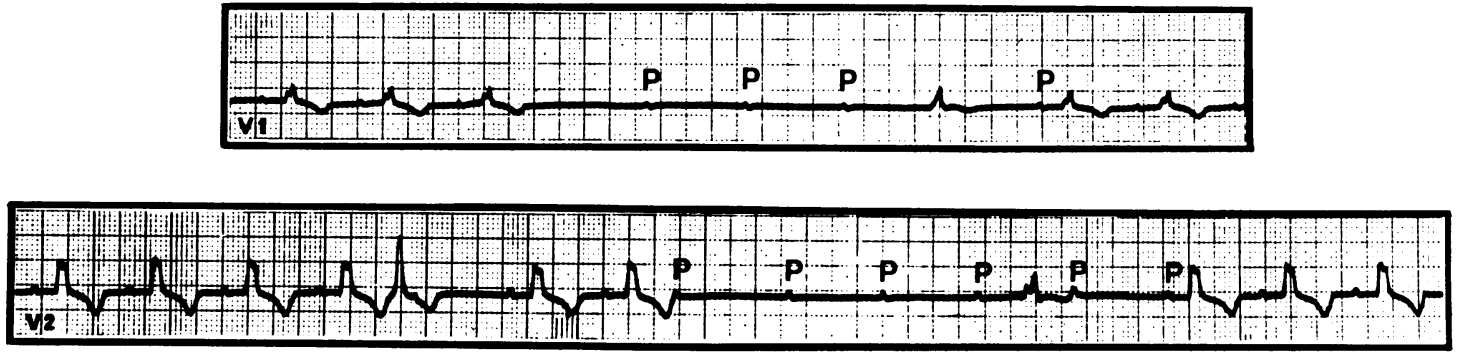

FI G. ro Short runs of paroxysmal AV block initiated (VI) by sinus depression and (V2) by a blocked atrial premature beat. 
conducted $\mathbf{P}$ wave; 3) intraventricular trifascicular block, with a normal PR interval and a prolonged HV time (Narula et al., 1971), indicating delayed conduction probably in the main left bundle or in its posterior division; 4) episodes of paroxysmal atrioventricular block interposed with $\mathbf{I}: \mathbf{I}$ atrioventricular conduction and complete atrioventricular block.

\section{Discussion}

Impulse propagation in incompletely repolarized fibres of the His-Purkinje system caused by prolongation of the refractory period, or in fibres which develop phase-4 depolarization, may be affected so as to result in significant delay or block.

Under certain experimental and clinical pathological conditions: hypoxia and ischaemia (Trautwein and Dudel, 1956); increased stretch (Dudel and Trautwein, 1954; Singer et al., 1967); and contusion of the intraventricular branching system (Kretz and Da Ruos, 1972), the cardiac cycle length variability constitutes an outstanding factor in the development of different forms of impaired conduction, making evident that both phase- 3 and phase- 4 block may be detected, differentiated, and their evolution determined by clinical (Massumi, I968) and experimental electrocardiography. Therefore, pronounced decrease in cardiac frequency may determine paradoxical blockages of branches or divisions, owing to the development of phase-4 depolarization (Case I, Fig. 2). Similarly, delay or interruption in the above-mentioned system may also be evidenced by slight prolongation of the cardiac cycle length (Case 2, Fig. 4) which has been attributed by Singer and Ten Eick (197I) to the probable combination of enhanced phase- 4 depolarization and diminished membrane responsiveness.

Since the ascending slope of spontaneous diastolic depolarization is gradual, the appearance of conducted sinoatrial beats with varying degrees of bundle-branch block aberrancy developing with increases in cycle length, may be attributed to atrial impulses reaching the affected fascicle at different levels of diastolic depolarization. Such electrocardiographic derangements in the left bundle-branch (Fig. 4) were clinically recorded. The reproducibility of such phenomenon in the canine intraventricular bundle-branch system was also achieved in our laboratory (Kretz, Da Ruos, and Leguizamón Palumbo, 1974). This finding confirms the hypothesis that different degrees of decremental conduction obtained with a slow heart rate are produced by the following basic mechanism: fluctuations in level of transmembrane potential caused by variations of spontaneous diastolic depolarization in the contusion affected cells of the corresponding fascicle. In almost all the cases presented in this paper (Table I) clear evidence of prolonged recovery associated with spontaneous diastolic depolarization was recorded (Fig. II), indicating that such electrophysiological mechanisms coexist, both at the level of the higher parts of the main intraventricular conduction fascicles and in their peripheral ramifications (Elizari, Lazzari, and Rosenbaum, 1973) as well.

The development of bradycardia-dependent block in the branching portion of the intraventricular conduction system, caused by prolongation of the cardiac cycle length caused by a Mobitz type I or II atrioventricular block, has been pointed out (von Hoesslin, 1923; Scherf and Scharf, 1948; Vesell and Lowen, 1963; Sherf and James, 1969; Sepúlveda, Rosselot, and Ahumada, 1969; Schamroth and Lewis, 1971; Friedberg, 1971; Mazzoleni and Fletcher, 1971; Gallagher et al., 1973). Clinical evidence of this association is shown in Fig. 6, strip B, where Luciani-Wenckebach periods, with varying degrees of left bundle-branch block aberrancy in the first sequence beat, are observed (Friedberg, 1972). Likewise, the coexistence of phase-4 block with Mobitz type I form of decremental conduction has been reproduced in both divisions of the canine left bundle-branch (Kretz and Da Ruos, 1972).

Considering that recent electrophysiological studies (Bailey et al., 1972; Myerburg, Nilsson, and Gelband, 1972) carried out on bundle-branch and Purkinje muscle preparations have indicated that spontaneous diastolic depolarization occurs within the bundle-branches, it can be expected that enhanced phase- 4 depolarization confined to a group of automatic cells within the main left bundlebranch, might create an ectopic pacemaker (Hoffman, 1966; Drake, Skom, and Singer, 1971). Narrow ventricular ectopic beats arising from such anatomical origin were recorded in one of our patients (Case 2, Fig. 5). This interpretation is based on Rosenbaum's classification of ventricular extrasystoles (Rosenbaum, 1969). Our case according to QRS pattern and classical criteria (SodiPallares, Bisteni, and Medrano, 1964) corresponds to pure incomplete right bundle-branch block configuration (Fig. $5 \mathrm{~B}$ ), thus suggesting a site of origin within the main left bundle-branch (Rosenbaum et al., 1970b; Puech et al., 1971).

Since narrow ventricular ectopic beats do arise at the ventricular level from the higher parts of the main intraventricular conducting fascicles, it may be assumed that when diastolic depolarization develops in such areas, an association of impaired conductivity is most likely; therefore transmission of 
A.

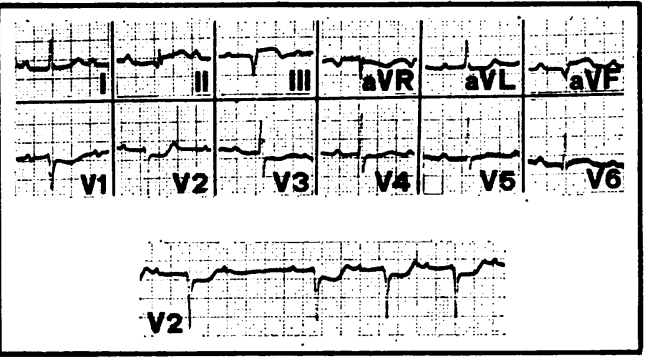

B.
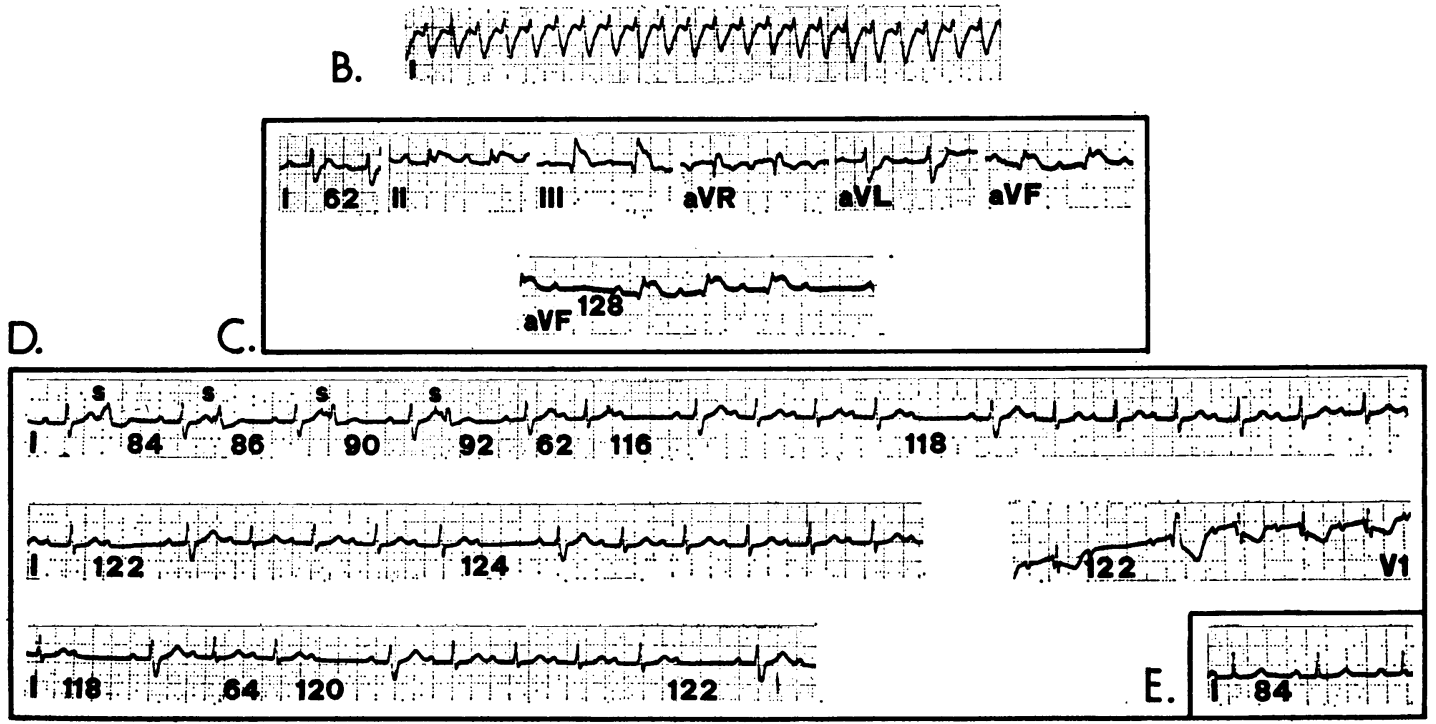

FIG. II (Case 6). Transient rate-dependent right bundle-branch block during the course of an acute myocardial infarction. Panel A. Twelve-lead electrocardiogram showing diaphragmatic infarction and Mobitz type I atrioventricular block. Panel B obtained the same day reveals ventricular tachycardia. After direct current cardioversion, a transient right bundle-branch block was recorded (panel C). In panel D (leads I and VI) recorded 2 minutes later, each long ventricular diastolic pause caused by an induced ventricular complex $(s)$ or by a dropped beat is followed by an atrial complex with a similar right bundle-branch block configuration (phase-4 block). Note progressively decreasing degrees of right bundle-branch aberrancy of beats closing cycles of $0.64 \mathrm{sec}$ or shorter in duration (phase-3 block). Since ischaemic injured Purkinje cells may develop generalized diastolic depolarization concomitantly with prolonged phase- 3 , consistent block of the impulse in the right bundle-branch can be explained by assuming the presence of two different mechanisms that alternate with each other. Normal intraventricular conduction was restored 4 minutes later (strip $E$ ).

the atrial impulse through such enhanced phase-4 areas must be delayed or blocked (Watanabe, 1971). This assumption appears to be strongly supported by the findings previously reported (Fig. 5A), where sinus beats showing variable degrees of bradycardia-dependent left bundle-branch block coexisted with narrow ventricular ectopic beats with pure incomplete right bundle-branch block. Variations in the spontaneous firing rate of such centres of impulse formation can be explained by changes in levels of diastolic membrane potential in conjunction with variations in the extent of phase- 4 depolarization and variability of the threshold potential (Singer et al., 1967) in the cells located within the boundaries of the main left bundlebranch.

The development of phase- 4 depolarization in the monofascicular pathway (His bundle), or in a 
branch or division confronted by blockage of the remaining fascicles, will give rise to bradycardiadependent atrioventricular block (Singer et al., 1967). Disturbance of the atrioventricular conduction assigned to this mechanism has been referred to in recent reports: in monofascicular atrioventricular block (Slama et al., 1969), in bifascicular atrioventricular block (Coumel et al., 197I), and in trifascicular atrioventricular block, both clinically (Rosenbaum et al., 1973c) and experimentally (Da Ruos et al., I97I).

All these, because of their clinical features, have been included in the paroxysmal atrioventricular block group (Sachs and Traynor, 1933), and are outstanding because of the sudden appearance of atrioventricular block, caused by acceleration or decrease of atrial frequency. Atrioventricular conduction is resumed after the escape of a subsidiary pacemaker, the latter keeping an adequate timing with the first atrial impulse which is conducted to the ventricles. These peculiarities observed in all our clinical (Fig. 7 and 10) and experimental (Da Ruos et al., 197I) cases lead us to assume that this ventricular escape beat would have the function of depolarizing by retrograde conduction the blocked phase- 4 fascicle, thus permitting the reinitiation of anterograde atrioventricular conduction (Rosenbaum et al., I973c).

From the findings in Tables $I$ and 2 it seems that the bradycardia-dependent bundle-branch and atrioventricular block have common characteristics: a) a premature blocked zone, b) another one of conduction, and c) a tardy block zone. The presence of late blocking evidenced in branches by a bradycardia-dependent block of the affected fascicle or a bradycardia-dependent atrioventricular block, when occurring in a normal or acquired monofascicular pathway, is significant. It may be inferred from the above that the existence of a common mechanism attributable to prominent phase- 4 depolarization appears to be a plausible explanation for the late blocking zone in bradycardia-dependent forms of impaired conduction.

In our cases of bradycardia-dependent atrioventricular block, supernormality cannot be invoked, since a wide range of atrioventricular conduction has been observed (Table 2) (Lewis and Master, 1924). In spite of the fact that repetitive concealed conduction of atrial impulses may provoke prolonged periods of ventricular asystole (Langendorf and Pick, 1964; Chung, 1971), this report establishes the close relation between the prolongation of the cardiac cycle length and the development of enhanced phase-4 depolarization as the underlying mechanism of the bradycardiadependent paroxysmal atrioventricular block. There- fore, it is unlikely that, in our cases, ventricular asystole may be attributed to concealed conduction (Moore, Knoebel, and Spear, 197I).

As chronic trifascicular atrioventricular block is often preceded by blockage in two or more of the three fascicles of the bundle-branch system (Rosenbaum et al., 1970a), the most probable site where bradycardia-dependent paroxysmal atrioventricular block will develop in patients with right bundlebranch block coexisting with left anterior or posterior hemiblock and a prolonged $\mathrm{HV}$ interval (Table 2) seems to be in the main left bundle or in one of its principal subdivisions. This has been experimentally proved in the canine heart (Da Ruos et al., 1972). Bradycardia-dependent paroxysmal atrioventricular block as a forerunner of complete atrioventricular block was almost invariably observed in our clinical cases. Therefore, an understanding of this type of impaired conduction may be clinically important because of the therapeutic value of cardiac pacemakers.

The advice and encouragement of Dr. F. Batlle, Director of the Department of Cardiology and Dr. C. A. Bertolasi, Chief of the Coronary Care Unit, Hospital Cosme Argerich, are gratefully acknowledged.

\section{References}

Bailey, J. C., Greenspan, K., Elizari, M. V., Anderson, G. J., and Fisch, C. (1972). Effects of acetylcholine on automaticity and conduction in the proximal portion of the His-Purkinje specialized conduction system of the dog. Circulation Research, 30, 210.

Barold, S. S., and Schamroth, L. (1973). Tachycardiadependent left bundle branch block associated with bradycardia-dependent variable left bundle branch block: a case report. Circulation, 48, 216.

Chung, E. K. (197I). A reappraisal of concealed atrioventricular conduction. American Heart fournal, 82, 408.

Comeau, W. J., Hamilton, J. G. M., and White, P. D. (1938). Paroxysmal bundle-branch block associated with heart disease; a review and an analysis of the literature, with 13 new cases and notes upon the influence of the vagus. American Heart fournal, 15, 276.

Coumel, P., Fabiato, A., Waynberger, M., Motte, G., Slama, R., and Bouvrain, Y. (1971). Bradycardia-dependent atrioventricular block. Fournal of Electrocardiology, 4, 168.

Da Ruos, H. O., Kretz, A., Elizari, M. V., Lazzari, J. O., and Rosenbaum, M. B. (197I). Bloqueo auriculo-ventricular experimental relacionado con despolarización diastólica espontanea en fase-4 (abstract). Medicina (Buenos Aires), 31, 545 .

Da Ruos, H. O., Kretz, A., Leguizamón Palumbo, J. R., Irigoyen, E. H., Sosa, J. M., and Schnetzer, E. (1972). Bloqueo A-V brádicardico-dependiente. Correlación clínico experimental (abstract). Medicina (Buenos Aires), 32, 715.

Drake, F., Skom, J., and Singer, D. H. (197I). Aberration occurring in conjunction with minimal changes in cycle length. Cited by Singer et al. in American fournal of Cardiology, 28, 381.

Dressler, W. (1959). Transient bundle branch block occurring during slowing of the heart beat and following gagging. American Heart fournal, 58, 760. 
Dudel, J., and Trautwein, W. (1954). Das Aktionpotential und Mechanogramm des Herzmuskels unter dem Einfluss der Dehnung. Cardiologia, 25, 344.

Elizari, M. V., Lazzari, J. O., and Rosenbaum, M. B. (1973). Phase- 3 and phase- 4 intermittent left anterior hemiblock. Chest, 62, 673 .

Elizari, M. V., Rosenbaum, M. B., Lazzari, J. O., Kretz, A., Da Ruos, H. O., and Leguizamón Palumbo, J. R. (I968). Evidencias clínicas de un nuevo mecanismo electrofisiológico en la patología de la conducción. Segundo Congreso Nacional de Cardiologia, Rosario, Argentina.

El-Sherif, N. (1972). Tachycardia-dependent versus bradycardia-dependent intermittent bundle-branch block. British Heart fournal, 34, 167.

Friedberg, H. D. (1971). Mechanism of the Wedensky phenomena in the left bundle branch. American fournal of Cardiology, 27, 698.

Friedberg, H. D. (1972). Observations on the duration of Wedensky facilitation in the left bundle branch. Fournal of Electrocardiology, 5, 185 .

Gallagher, J. J., Damato, A. N., Varghese, P. J., Caracta, A. R., Josephson, M. E., and Lau, S. H. (I973). Alternative mechanisms of apparent supernormal atrioventricular conduction. American fournal of Cardiology, 31, 362.

Garcia, H., and Rosenbaum, M. B. (1972). El 'efecto fuelle' en los bloqueos intermitentes de rama. Revista Argentina de Cardiología, 40, 75.

Hoffman, B. F. (I966). The electrophysiology of the heart muscle and the genesis of arrhythmias. In Mechanisms and Therapy of Cardiac Arrhythmias, p. 27. Ed. by L. S. Dreifus and W. Likoff. Grune and Stratton, New York.

Katz, L. N., and Pick, A. (1956). Clinical Electrocardiography, Part I. The Arrhythmias. Lea and Febiger, Philadelphia.

Kretz, A., and Da Ruos, H. O. (1972). Experimental LucianiWenckebach phenomenon in the anterior and posterior divisions of the left bundle branch of the canine heart. American Heart fournal, 84, 513.

Kretz, A., Da Ruos, H. O., and Leguizamón Palumbo, J. R. (1974). Conduction disturbances due to enhanced phase 4 depolarization in the bundle branches of the canine heart. To be published.

Langendorf, R., and Pick, A. (1964). Causes and mechanisms of ventricular asystole in advanced A-V block. In Sudden Cardiac Death, p. 97. Ed. by B. Surawicz. Grune and Stratton, New York.

Lewis, T., and Master, A. M. (1924). Supernormal recovery phase, illustrated by two clinical cases of heart-block. Heart, 11, 37I.

Massumi, R. A. (1968). Bradycardia dependent bundle branch block: a critique and proposed criteria. Circulation, 38, ro66.

Mazzoleni, A., and Fletcher, E. (1971). Facilitation of conduction in left bundle of His. British Heart fournal, 33, 970.

Moore, E. N., Knoebel, S. B., and Spear, J. F. (I97I). Concealed conduction. American fournal of Cardiology, 28, 406.

Myerburg, R. J., Nilsson, K., and Gelband, H. (I972). Physiology of canine intraventricular conduction and endocardial excitation. Circulation Research, 30, 217.

Narula, O. S., Scherlag, B. J., Samet, P., and Javier, R. P. (I97I). Atrioventricular block. Localization and classification by His bundle recordings. American fournal of Medicine, 50, 146.

Puech, P., Grolleau, R., Latour, H., Dufoix, R., Cabasson, J., and Robin, J. (I97I). Enregistrement de l'activité de la branche gauche du faisceau de His par voie endocavitaire. Archives des Maladies du Coeur et des Vaisseaux, 64, ro.

Rosenbaum, M. B. (1969). Classification of ventricular extrasystoles according to form. Fournal of Electrocardiology, 2, 289.

Rosenbaum, M. B., Elizari, M. V., Kretz, A., and Taratuto,
A. L. (1970a). Anatomical basis of A-V conduction disturbances. Geriatrics, 25, No. II, 132.

Rosenbaum, M. B., Elizari, M. V., Lazzari, J. O., Halpern, M. S., Nau, G. J., and Levi, R. J. (r973a). The physiological basis of intermittent bundle branch block. In Cardiac Arrhythmias, p. 349. Ed. by L. S. Dreifus and W. Likoff. Grune and Stratton, New York and London.

Rosenbaum, M. B., Elizari, M. V., Lazzari, J. O., Halpern, M. S., Nau, G. J., and Levi, R. J. (I973b). The mechanism of intermittent bundle branch block: relationship to prolonged recovery, hypopolarization and spontaneous diastolic depolarization. Chest, 63, 666 .

Rosenbaum, M. B., Elizari, M. V., Levi, R. J., and Nau, G. J. (1973c). Paroxysmal atrioventricular block related to hypopolarization and spontaneous diastolic depolarization. Chest, 63, 678.

Rosenbaum, M. B., Halpern, M. S., Nau, G. J., Elizari, M. V., and Lazzari, J. O. (1970b). The mechanism of ventricular ectopic beats. In Symposium on Cardiac Arrhythmias, p. 223. Ed. by E. Sandøe, E. FlenstedJensen, and K. H. Olesen. AB Astra, Södertälje, Sweden.

Sachs, A., and Traynor, R. L. (1933). Paroxysmal complete auriculo-ventricular heart-block. American Heart fournal, 9, 267.

Sarachek, N. S. (1970). Bradycardia-dependent bundle branch block. American fournal of Cardiology, 25, 727.

Schamroth, L., and Lewis, C. M. (I97I). Normalization of a bundle branch block pattern in early beats. Fournal of Electrocardiology, 4, 199.

Scherf, D., and Scharf, M. M. (1948). Supernormal phase of intraventricular conduction. American Heart fournal, 36, 621.

Scherlag, B. J., Lau, S. H., Helfant, R. H., Berkowitz, W. D., Stein, E., and Damato, A. N. (1969). Catheter technique for recording His bundle activity in man. Circulation, 39, 13.

Sherf, L., and James, T. N. (1969). A new electrocardiographic concept: synchronized sinoventricular conduction. Diseases of the Chest, 55, 127.

Sepúlveda, G., Rosselot, M. D., and Ahumada, J. (1969). Second degree atrioventricular block with intermittent right plus left anterior branch block. Diseases of the Chest, $56,553$.

Singer, D. H., Lazzara, R., and Hoffman, B. F. (I967). Interrelationships between automaticity and conduction in Purkinje fibers. Circulation Research, 21, 537.

Singer, D. H., and Ten Eick, R. E. (197I). Aberrancy: electrophysiologic aspects. American fournal of Cardiology, 28, 38I.

Slama, R., Coumel, P., Motte, G., Fanjoux, J., Auperrin, A., and Penther, P. (1969). Etude électrocardiographique de l'installation et de la disparition du trouble de conduction dans deux cas de bloc auriculo-ventriculaire paroxystique. Archives des Maladies du Coeur et des Vaisseaux, 62, ror.

Sodi-Pallares, D., Bisteni, A., and Medrano, G. A. (I964). Electrocardiografia y vectocardiagrafia deductivas, Vol. I. La Prensa Médica Mexicana, México, D. F.

Trautwein, W., and Dudel, J. (1956). Aktionpotential und Kontraktion des Herzmuskels im Sauerstoffmangel. Pflügers Archiv für die gesante Physiologie des Menschen und der Tiere, 263, 23.

Vesell, H., and Lowen, G. (1963). Bundle branch block on cardiac slowing at a critical slow heart rate. American Heart fournal, 66, 329.

von Hoesslin, H. (1923). Uber einer besonderen Fall von Störung der Reizleitung und der Reizbarkeit des Herzens. Deutsches Archiv für Klinische Medizin, 141, 348.

Watanabe, Y. (197I). Reassessment of parasystole. American Heart fournal, 81, 45I. 
Weidmann, S. (1955). The effect of the cardiac membrane potential on the rapid availability of the sodium-carrying system. Fournal of Physiology, 127, 213.

Wennemark, J. R., and Ruesta, V. J. (197I). Microelectrode study of $2: 1$ conduction block in canine Purkinje fibers. fournal of Electrocardiology, 4, 50.

West, T. C. (1955a). Ultramicroelectrode recording from the cardiac pacemaker. Fournal of Pharmacology and Experimental Therapeutics, $115,283$.

West, T. C. (I955b). Auricular cellular potentials: ultramicroelectrode recording of drug effects on nodal and extranodal regions (abstract). Federation Proceedings, 14, 393.

Requests for reprints to Dr. Andres Kretz, Arenales 3504 ler Piso, Buenos Aires, Argentina. 